Куликова Наталия Николаевна

кандидат экономических наук, доцент, доцент кафедры экономики

и инновационного предпринимательства

Московского технологического университета

\section{СОВРЕМЕННОЕ СОСТОЯНИЕ И ТЕНДЕНЦИИ РАЗВИТИЯ ЭЛЕКТРОННОЙ ПРОМЫШЛЕННОСТИ В РОССИИ}

Аннотация:

Возможности электронной промышленности определяют технологическую независимость, обороноспособность, информационную безопасность страны, а также жизнедеятельность общества. Без собственных микроэлектронных компонентов Россия не может быть современной державой и развивать другие высокотехнологичные и наукоемкие отрасли. В статье проведен анализ состояния отечественной электронной промышленности. Особое внимание уделено микроэлектронике как самому дuнамичному сегменту экономики в мире и стратеаически важной отрасли для нашего государства. Анализ статистических данных свидетельствует о том, что доля России в мировом объеме производства микроэлектронных компонентов незначительна и составляет менее 1 \%. Выявлены проблема обеспеченности российских предприятий отечественными электронными компонентами и зависимость электроники от импорта. Слабые позиции Российской Федерации относительно большинства стран мира объясняются технологическим отставанием, сильной зависимостью от государственных заказов и дефицитом молодого персонала.

Ключевые слова:

электронная промышленность, микроэлектроника, объем производства, прирост, экспорт, импорт.
Kulikova Natalia Nikolaevna

PhD in Economics, Associate Professor, Department of Economics and Innovative Entrepreneurship, Moscow Technological University

\section{MODERN STATE AND DEVELOPMENT TRENDS OF ELECTRONIC INDUSTRY IN RUSSIA}

Summary:

The capabilities of the electronic industry determine the technological independence, defense capacity, information security of the country and the society activities. Russia cannot be a modern power and develop other high-tech and knowledge-based industries without its own microelectronic components. The paper analyzes the state of the Russian electronics industry. The research focuses on microelectronics as the most dynamic branch of the economy in the world and a strategically important industry for this country. Analysis of statistical data shows that Russia's share in the world production of microelectronic components is insignificant and less than $1 \%$. The problem of providing Russian enterprises with the domestic electronic components and the dependence of electronics on imports is revealed. Russia's weak position in relation to the majority of states is explained by technological backwardness, strong dependence on government orders and a shortage of young personnel.

Keywords: electronic industry, microelectronics, production volume, growth, exports, imports.

Электронная промышленность - наиболее наукоемкая и технологически сложная отрасль современного машиностроения, выпускающая электронные компоненты [1]. Главными гражданскими потребителями последних являются производители аппаратуры цифрового теле- и радиовещания, медицинской, научной и бытовой аппаратуры, средств обучения, автомобильной и промышленной электроники, энергетического оборудования и др. Развитие электронной промышленности на основе использования отечественных электронных компонентов обеспечивает независимость в важнейших областях информатизации, телекоммуникации и связи. Только собственные проектирование и производство в данном сегменте позволяют разрабатывать и создавать специализированную технику для государственных структур, перспективные образцы вооружения, навигационную аппаратуру, военную и специальную технику и системы безопасности, а также экспортировать оружие.

Электронная промышленность является одной из наиболее динамично развивающихся отраслей в мировой экономике. В среднем темпы прироста объемов мировой электронной промышленности значительно выше таковых мирового промышленного производства (таблица 1).

Самой наукоемкой и технологически сложной сферой электронной промышленности выступает микроэлектроника, качественное развитие которой во многом обеспечило научно-технический прогресс во второй половине XX в. Микроэлектроника - это область электроники, включающая исследование, конструирование, производство и применение электронных функциональных узлов, блоков и устройств в микроминиатюрном интегральном исполнении [2]. В настоящее время 90 \% инновационных решений базируются на продукции микроэлектроники [3]. Так, на ней основаны передовые производственные технологии - технологические процессы, включающие машины, аппараты, оборудование и приборы. Поэтому большинство развитых и развивающихся стран мира поддерживают микроэлектронику, признавая ее ключевым фрактором инноваций и социально-экономического развития [4]. 
Таблица 1 - Среднегодовые темпы прироста объемов мирового рынка электроники и мирового промышленного производства в целом [5]

\begin{tabular}{|c|c|c|}
\hline Период & $\begin{array}{c}\text { Среднегодовой темп прироста объемов } \\
\text { мирового рынка электроники, \%* }\end{array}$ & $\begin{array}{c}\text { Среднегодовой темп прироста объемов } \\
\text { мирового промышленного производства, \%** }\end{array}$ \\
\hline $1961-1970$ & 10,0 & 5,00 \\
\hline $1971-1980$ & 15,2 & 3,60 \\
\hline $1981-1990$ & 13,1 & 3,00 \\
\hline $1991-2000$ & 7,2 & 2,30 \\
\hline $2001-2010$ & 2,1 & 3,34 \\
\hline $2011-2015$ & 3,8 & 1,86 \\
\hline
\end{tabular}

* Gartner $и$ iSuppli (IHS).

** CIA World Factbook $и$ World Economic and Social Survey.

Мировые объемы производства микроэлектронных компонентов за 20 лет возросли почти в 3 раза (таблица 2).

Таблица 2 - Мировой объем производства микроэлектронных компонентов [6]

\begin{tabular}{|c|c|c|}
\hline Год & $\begin{array}{c}\text { Мировой объем производства } \\
\text { микроэлектронных компонентов, млрд долл. }\end{array}$ & Темп прироста, \% \\
\hline 1998 & 125,2 & 15,02 \\
\hline 1999 & 144,0 & 41,67 \\
\hline 2000 & 204,0 & $-31,86$ \\
\hline 2001 & 139,0 & 1,22 \\
\hline 2002 & 140,7 & 18,27 \\
\hline 2003 & 166,4 & 28,49 \\
\hline 2004 & 213,8 & 10,06 \\
\hline 2005 & 235,3 & 5,14 \\
\hline 2006 & 247,4 & 3,31 \\
\hline 2007 & 255,6 & $-2,74$ \\
\hline 2008 & 248,6 & $-20,35$ \\
\hline 2009 & 198,0 & 38,38 \\
\hline 2010 & 274,0 & 12,01 \\
\hline 2011 & 306,9 & $-2,90$ \\
\hline 2012 & 298,0 & 5,91 \\
\hline 2013 & 315,6 & 8,56 \\
\hline 2014 & 342,6 & $-2,28$ \\
\hline 2015 & 334,8 & 1,46 \\
\hline 2016 & 339,7 & $6,27^{*}$ \\
\hline 2017 & $361,0^{*}$ & $2,22^{*}$ \\
\hline 2018 & $369,0^{*}$ & \\
\hline
\end{tabular}

*Прогноз.

Основная доля рынка микроэлектронных компонентов принадлежит странам Юго-Восточной Азии (Китаю, Малайзии, Тайваню, Сингапуру, Южной Корее и др.) - около 61 \%; государствам Северной и Южной Америки - 19; странам Европы и Японии - по 10 \%. За последние 10 лет доля государств Юго-Восточной Азии в структуре мирового рынка микроэлектроники увеличилась на $14 \%$, Северной и Южной Америки - на 1 \%. Рыночные доли европейских стран и Японии, напротив, сократились на 6 и 9 \% соответственно. По оценкам агентства Frost \& Sullivan, в ближайшие 5 лет первые позиции в отрасли сохранят за собой Китай, Малайзия, Тайвань, Сингапур, Южная Корея и США [7].

По данным Gartner, 25 крупнейших производителей занимают 75,9 \% глобального рынка, среди них Intel, Samsung Electronics, Qualcomm, SK Hynix, Broadcom Ltd, Micron Technology, Texas Instruments, Toshiba, NXP, Media Tek [8].

Представим объемы российского рынка микроэлектронных компонентов за 2002-2016 гг. (таблица 3). В 2016 г. доля России в мировом объеме производства микроэлектронных компонентов составила 0,68 \% [9].

Основными причинами отрицательных и низких темпов прироста производства микроэлектронных компонентов в России являются технологическое отставание и отставание по параметрам. Например, передовые отечественные производители микроэлектроники в настоящее время осваивают технологии уровня 65 нм на пластинах 200 мм, а в развитых странах уже применяется технология уровня 16 нм на пластинах до 300 мм и начаты разработка уровня 10-7 нм и переход на пластины размером 450 мм. В свою очередь большинство российских дизайн-центров по компетенциям могут выполнить проектные работы только до технического уровня 180 или 90 нм, сейчас стартовало освоение технологии проектирования уровня 45-28 нм. 
Таблица 3 - Объем производства микроэлектронных компонентов в России [10]

\begin{tabular}{|c|c|c|c|}
\hline Год & $\begin{array}{c}\text { Российский объем производства } \\
\text { микроэлектронных компонентов, } \\
\text { млн долл. }\end{array}$ & $\begin{array}{c}\text { Темп } \\
\text { прироста, \% }\end{array}$ & $\begin{array}{c}\text { Доля России в мировом объеме } \\
\text { поизводства микроэлектронных } \\
\text { компонентов, \% }\end{array}$ \\
\hline 2002 & 624 & - & 0,44 \\
\hline 2003 & 816 & 30,77 & 0,49 \\
\hline 2004 & 988 & 21,08 & 0,46 \\
\hline 2005 & 1176 & 19,03 & 0,50 \\
\hline 2006 & 1431 & 21,68 & 0,58 \\
\hline 2007 & 1861 & 30,05 & 0,73 \\
\hline 2008 & 2163 & 16,23 & 0,87 \\
\hline 2009 & 1406 & $-35,00$ & 0,71 \\
\hline 2010 & 1898 & 34,99 & 0,69 \\
\hline 2011 & 2344 & 23,50 & 0,76 \\
\hline 2012 & 2522 & 7,59 & 0,85 \\
\hline 2013 & 2573 & 2,02 & 0,82 \\
\hline 2014 & 2785 & 8,24 & 0,81 \\
\hline 2015 & 2387 & $-14,29$ & 0,71 \\
\hline 2016 & 2309 & $-3,27$ & 0,68 \\
\hline
\end{tabular}

Кроме того, производители микроэлектронных компонентов очень сильно зависимы от государственных заказов на внутреннем рынке сбыта (превалируют заказы на поставки военной и индустриальной электроники). При этом в большинстве развитых государств главный спрос формируется в частном секторе, а государственные заказы составляют примерно 14 \% в структуре потребления микроэлектроники в мире. По оценкам агентства Frost \& Sullivan, сегментация российских потребителей микроэлектронных компонентов (микросхем, чипов, полупроводниковых составляющих) в 2016 г. распределяется следующим образом: 45 \% производимых в стране микроэлектронных компонентов потребляют предприятия авиационной и оборонной промышленности; 32 - компании, работающие в сфере энергетики, медицины и приборостроения; 11 малые и средние фрирмы, специализирующиеся на выпуске потребительской электроники; 5 - на производстве карт памяти и RFID-меток; 3 - выпуске ПК, серверного оборудования; 2 - занятые в сорере «Интернета вещей», по 1 \% - в автомобилестроении и телекоммуникационном оборудовании. Для сравнения, в развитых странах мира основной спрос на микроэлектронные компоненты фрормируется в сегменте цифрового телевидения - в среднем 31,5 \%; производства персональных компьютеров - 29,5; автомобилестроения - 11,6 \% [11].

Согласно отчету аналитической компании IC Insights, в мире в 2016 г. лидировали два сегмента потребителей микроэлектронных компонентов: мобильные телефоны (мировой объем производства микроэлектронных компонентов в 2016 г. составил 74,2 млрд долл., прирост 2 \% по сравнению с цифрами 2015 г.) и вычислительная техника (в 2016 г. объем - 54,6 млрд долл., снижение -5 \% по сравнению с показателями 2015 г.). Кроме того, выделим четыре сегмента рынка микроэлектронных компонентов, которые имели наибольший прирост в 2016 г., \%: «Интернет вещей» - 19 (мировой объем выпуска компонентов - 12,8 млрд долл.), автоэлектроника 12 (22,9 млрд), медицина - 9 (4,9 млрд), цифровое телевидение - 4 (12,9 млрд долл.) [12].

С точки зрения стимулирования спроса на продукцию производственных предприятий, по данным агентства Frost \& Sullivan, в ближайшие 5 лет ключевыми драйверами развития мировой микроэлектроники станут автомобильная и телекоммуникационная промышленность, робототехника, индустрия здравоохранения, сегменты потребительской электроники и «Интернета вещей». Распространяются и набирают рыночную силу устройства дополненной и виртуальной реальности, более мощных технологий для работы с большими объемами данных, выпуск энергоэффективных технологий (в том числе OLED), носимых устройств. Также существенное влияние на развитие и рост мирового рынка микроэлектроники окажут промышленный «Интернет вещей» и так называемый «Интернет медицинских вещей» [13].

Конкурентоспособность национальной экономики напрямую зависит от доли высокотехнологичных отраслей страны в общем мировом объеме экспорта и импорта. Россия значительно уступает в области экспорта высокотехнологичных товаров другим государствам. Ежегодно увеличивается негативный разрыв в темпах прироста экспорта высокотехнологичной продукции России и многих стран мира, в частности США, Южной Кореи, Японии, Германии и др. Доля РФ к уровню экспорта США в 2015 г. составила 1,74 \%. Естественно, это ведет к значительным экономическим потерям. По данным Всемирного банка, Россия на рынке высокотехнологичной продукции занимает 0,44 \% (таблица 4). В отличие от показателей Китая и развитых стран экспорт высокотехнологичных изделий из РФ незначителен. 
Таблица 4 - Доли стран в мировом объеме экспорта высокотехнологичной продукции в 2015 г., \% [14]

\begin{tabular}{|l|c|}
\hline \multicolumn{1}{|c|}{ Страна } & Доля в мировом экспорте высокотехнологичной продукции \\
\hline Китай & 25,31 \\
\hline Германия & 8,47 \\
\hline США & 7,05 \\
\hline Сингапур & 5,98 \\
\hline Южная Корея & 5,78 \\
\hline Франция & 4,76 \\
\hline Япония & 4,18 \\
\hline$\ldots$ & \\
\hline Россия & 0,44 \\
\hline$\ldots$ & \\
\hline
\end{tabular}

Эксперты дают разные оценки объемам экспорта российских высокотехнологичных товаров. Так, по данным Росстата, доля высокотехнологичных товаров в общем объеме экспорта России в 2015 г. составила 5,3 \% (таблица 5) [15]. Анализ структуры экспорта РФ высокотехнологичной продукции показывает, что поставки электроники и телекоммуникационного оборудования в 2015 г. сократились на 39,4 \% по сравнению с цифрами 2014 г.

Таблица 5 - Экспорт РФ высокотехнологичной продукции, млн долл. [16]

\begin{tabular}{|c|c|c|c|c|c|c|}
\hline \multirow{2}{*}{ Показатель } & \multicolumn{6}{|c|}{ Экспорт } \\
\hline & 2010 & 2011 & 2012 & 2013 & 2014 & 2015 \\
\hline Всего (внешняя торговля РФ) & 392674 & 515409 & 527434 & 521835 & 496806 & 341467 \\
\hline $\begin{array}{l}\text { в том числе высокотехнологичная продукция - } \\
\text { всего } \\
\text { из нее }\end{array}$ & 13770 & 17164 & 15987 & 18526 & 19043 & 18233 \\
\hline товары авиакосмической промышленности & 6079 & 7233 & 5981 & 7545 & 5912 & 7436 \\
\hline компьютерно-офисная техника & 118 & 253 & 267 & 356 & 1772 & 1582 \\
\hline $\begin{array}{l}\text { электроника и телекоммуникационное } \\
\text { оборудование }\end{array}$ & 854 & 1208 & 1078 & 1207 & 1600 & 969 \\
\hline фармацевтика & 115 & 171 & 215 & 235 & 266 & 224 \\
\hline прочие товары & 6603 & 8299 & 8447 & 9184 & 9492 & 8022 \\
\hline
\end{tabular}

Позиции России в мировом объеме экспорта электроники слабы. Однако наибольшая зависимость от импортной высокотехнологичной продукции за 2010-2015 гг. наблюдается по таким видам, как электроника и телекоммуникационное оборудование (таблица 6). Для РФ это самое уязвимое место, поскольку электроника стимулирует развитие ракетно-космической промышленности, авиа- и станкостроения, транспортного и сельскохозяйственного машиностроения и других отраслей. Так, доля высокотехнологичных товаров в общем объеме импорта России в 2015 г. составила 14,9 \%. По сравнению с данными 2014 г. в 2015 г. отмечается снижение объемов импорта на 37,3 \% и импорта высокотехнологичных товаров - на 30,0 \%.

Таблица 6 - Импорт РФ высокотехнологичной продукции, млн долл. [17]

\begin{tabular}{|l|c|c|c|c|c|c|}
\hline \multicolumn{1}{|c|}{ Показатель } & \multicolumn{5}{c|}{ Импорт } \\
\cline { 2 - 7 } & $\mathbf{2 0 1 0}$ & $\mathbf{2 0 1 1}$ & $\mathbf{2 0 1 2}$ & $\mathbf{2 0 1 3}$ & $\mathbf{2 0 1 4}$ & $\mathbf{2 0 1 5}$ \\
\hline Всего (внешняя торговля РФ) & 245680 & 318555 & 335771 & 341269 & 307875 & 192954 \\
\hline $\begin{array}{l}\text { в том числе высокотехнологичная продукция - } \\
\begin{array}{l}\text { всего } \\
\text { из нее }\end{array}\end{array}$ & 30680 & 38289 & 40265 & 39356 & 41161 & 28822 \\
\hline товары авиакосмической промышленности & 4319 & 6589 & 5620 & 6678 & 8363 & 4003 \\
\hline компьютерно-офисная техника & 6024 & 6572 & 7107 & 6139 & 6536 & 5825 \\
\hline $\begin{array}{l}\text { электроника и телекоммуникационное } \\
\text { оборудование }\end{array}$ & 10301 & 12552 & 12930 & 12249 & 13133 & 9537 \\
\hline фармацевтика & 3454 & 3982 & 4222 & 4655 & 4234 & 3031 \\
\hline прочие товары & 6582 & 8594 & 10385 & 9635 & 8895 & 6426 \\
\hline
\end{tabular}

По оценкам ООО «Совэл», отечественные производители микроэлектронных компонентов удовлетворяют только 31 \% внутреннего спроса (таблица 7) [18]. Ключевыми поставщиками электронных компонентов на российский рынок являются зарубежные компании преимущественно из стран Азии, \%: Китай - 23, Малайзия - 14, Тайвань - 13, Южная Корея - 11, Коста-Рика - 8 , Таиланд - 5 [19]. 
Таблица 7 - Объемы продаж отечественных и импортных электронных компонентов на российском рынке [20]

\begin{tabular}{|c|c|c|c|c|c|}
\hline \multirow{2}{*}{ Показатель } & \multicolumn{2}{|c|}{$\begin{array}{c}\text { Объем продаж, } \\
\text { млн долл. }\end{array}$} & \multirow{2}{*}{$\begin{array}{c}\text { Темп } \\
\text { прироста, \% }\end{array}$} & \multicolumn{2}{c|}{$\begin{array}{c}\text { Доля в общем } \\
\text { объеме продаж, \% }\end{array}$} \\
\cline { 2 - 6 } & $\mathbf{2 0 1 4}$ & $\mathbf{2 0 1 5}$ & $\mathbf{2 0 1 4}$ & $\mathbf{2 0 1 5}$ \\
\hline Отечественные электронные компоненты & 890,5 & 748,0 & $-16,0$ & 31,8 & 31,3 \\
\hline Импортные электронные компоненты & 1912,5 & 1639,0 & $-14,3$ & 68,2 & 68,7 \\
\hline
\end{tabular}

Для изменения ситуации требуются усиление позиций отечественных производителей микроэлектронных компонентов на национальном рынке и укрепление научно-производственного потенциала отрасли. Россия должна обеспечить собственные проектирование и разработку ключевых микроэлектронных компонентов для энергоэфффективных систем (в том числе выпуск преобразователей и выпрямителей напряжения для элементов питания и зарядных устройств, устройств для управления питанием и контролеров для светодиодного освещения), автомобильной отрасли, медицины, безопасности, промышленной электроники (химического сегмента, машиностроения, сельского хозяйства, биотехнологий и т. д.), аэрокосмической и оборонной отраслей, рынка телекоммуникаций (в том числе микросхем и чипов сим-карт), транспорта (транспортных электронных компонентов для метрополитена, проект «Эра ГЛОНАСС»), банковской сфреры (проект «Универсальная электронная карта»), паспортно-визовых документов (электронных паспортов).

Новые разработки и их дальнейшее эфффективное использование должны быть обеспечены кадровыми ресурсами, измеряемыми количественно через показатель численности персонала, занятого исследованиями и реализацией [21]. Главным сдерживающим фрактором развития микроэлектроники является необеспеченность сотрудниками. Сегодня наблюдается сокращение числа занятых в микроэлектронике, связанное с дефицитом молодых кадров. Так, в 2015 г. средний возраст работников отрасли составлял 48 лет. Анализ возрастной структуры показывает, что свыше $25 \%$ научных сотрудников, специалистов и рабочих относятся к возрастной категории 50 лет и более [22].

При решении этой проблемы необходимо помнить, что микроэлектроника - отрасль, имеющая высокую стратегическую значимость для национальной безопасности, поэтому здесь не может быть применена практика привлечения высококвалифицированных иностранных специалистов и научных сотрудников. В данном направлении требуется масштабная и многоплановая работа по подготовке только собственных профессиональных кадров, укреплению научных коллективов и фоормированию стратегического кадрового потенциала ученых и исследователей.

Таким образом, на основе приведенных данных можно судить о серьезном отставании отечественной микроэлектроники от большинства стран мира. Неспособность отечественных предприятий удовлетворить внутренний спрос несет для нашего государства серьезные угрозы и ведет к еще большей зависимости экономики от импорта.

\section{Ссылки и примечания:}

1. Рынок производственно-технологического направления «Разработка и производство электронных компонентов, узлов и блоков» : отчет по маркетинговому исследованию. М., 2008. 106 с.

2. Котлярский А.И. Промышленная электроника : учебник для вузов. 2-е изд., перераб. и доп. М., 1984. 284 с.

3. Механик А. У волны растут мозги, глаза и руки [Электронный ресурс] // Эксперт. 2012. № 25 (808). URL: http://expert.ru/expert/2012/25/u-volnyi-rastut-mozgi-glaza-i-ruki (дата обращения: 05.12.2017).

4. Development of Microelectronics in the Circumstances of the Innovative and Technological Growth of the Russian Economy / T.P. Rakhlis, N.V. Skvortsova, S.V. Koptyakova, N.R. Balynskaya // International Business Management. 2016. Vol. 10, no. 4. P. 401-407.

5. Составлено автором на основе данных Gartner и iSuppli (IHS), CIA World Factbook $и$ World Economic and Social Survey.

6. Составлено автором на основе данных компании Gartner.

7. Состояние и перспективы мирового и российского рынка микроэлектроники [Электронный pecypc]. URL: https://rb.ru/media/reports/FS_Мировои_и_россиискии_рынок_микроэлектроники.pdf (дата обращения: 05.12.2017).

8. Карасев С. Объем рынка полупроводниковых микросхем достиг 340 млрд долл. [Электронный ресурc]. URL: https://3dnews.ru/946211 (дата обращения: 05.12.2017).

9. Юртайкин С. Доля российского рынка микроэлектроники в мировом не превышает 1 \% [Электронный ресурc]. URL: https://newsland.com/user/4297805012/content/dolia-rossiiskogo-rynka-mikroelektroniki-v-mirovom-ne-prevyshaet1/5876579 (дата обращения: 05.12.2017)

10. Составлено автором на основе следующих источников: Отчет исследования российского рынка электронных компонентов. М., 2016. 119 с. ; Юртайкин С. Указ. соч.

11. Состояние и перспективы ...

12. Рост рынка микросхем по сегментам [Электронный ресурс]. https://www.soel.ru/novosti/2016/rost rynka mikroskhem po segmentam/ (дата обращения: 05.12.2017).

13. Мировой рынок микроэлектроники вырастет на 6,5\% [Электронный ресурc]. URL: http://www.vestifinance.ru/articles/86762 (дата обращения: 05.12.2017).

14. Составлено автором на основе данных Всемирного банка.

15. Российский статистический ежегодник. 2016 : статистический сборник. М., 2016. 725 с.

16. Там же. С. 624,633 . 
17. Там же.

18. Отчет исследования российского рынка ...

19. Седых И.А. Микроэлектроника и развитие бесконтактных платежей в РФ [Электронный ресурс]. M., 2016. 77 с. URL: https://dcenter.hse.ru/data/2017/01/31/1114338520/Микроэлектроника и бесконтактные платежи 2016.pdf (дата обращения: 05.12.2017).

20. Отчет исследования российского рынка ...

21. О состоянии инноваций в РФ / А.В. Сказочкин, С.В. Кумакова, Е.П. Константинова, Г.А. Токарева и др. // Экономические исследования и разработки. 2016. № 3. С. 19-70.

22. Седых И.А. Указ. соч.

\section{References:}

Karasev, S 2017, The amount of the semiconductor chip market reached \$ 340 billion, viewed 05 December 2017, $<$ https://3dnews.ru/946211>, (in Russian).

Kotlyarsky, Al 1984, Industrial electronics, textbook, 2nd ed., Moscow, 284 p., (in Russian).

Mekhanik, A 2012, 'A wave will have brains, eyes and hands', Ekspert, no. 25 (808), viewed 05 December 2017, <http://expert.ru/expert/2012/25/u-volnyi-rastut-mozgi-glaza-i-ruki>, (in Russian).

Rakhlis, TP, Skvortsova, NV, Koptyakova, SV \& Balynskaya, NR 2016, 'Development of Microelectronics in the Circumstances of the Innovative and Technological Growth of the Russian Economy', International Business Management, vol. 10, no. 4, pp. 401-407.

Russian Electronics Market Research Report 2016, Moscow, 119 p., (in Russian)

Russian Statistical Yearbook 2016: a statistical compilation 2016, Moscow, 725 p., (in Russian).

Sedykh, IA 2016, Microelectronics and distance payment development in the Russian Federation, Moscow, 77 p., viewed 05 December 2017, <https://dcenter.hse.ru/data/2017/01/31/1114338520/Микроэлектроника и бесконтактные платежи 2016.pdf>, (in Russian).

Skazochkin, AV, Kumakova, SV, Konstantinova, EP \& Tokareva, GA (et al.) 2016, 'The status of innovations in the Russian Federation', Ekonomicheskiye issledovaniya i razrabotki, no. 3, pp. 19-70, (in Russian).

The industrial and technological market "Development and manufacture of electronic components, elements and modules": a report on marketing research 2008, Moscow, 106 p., (in Russian).

Yurtaikin, S 2017, The share of the Russian microelectronics market of the global market does not exceed 1\%, viewed 05 December 2017, <https://newsland.com/user/4297805012/content/dolia-rossiiskogo-rynka-mikroelektroniki-v-mirovom-ne-prevyshaet-1/5876579>, (in Russian). 